\title{
Impact of global dimming on reference evapotranspiration in Hai River basin, China
}

\author{
NA ZHAO, XIAOFAN ZENG \& HUAIWEI SUN \\ School of Hydropower and Information Engineering, Huazhong University of Science and Technology, Wuhan, Hubei \\ Province, 430074, China \\ na.zhao.2011@mail.hust.edu.cn
}

\begin{abstract}
Global radiation can impact the surface energy balance and hydrological cycle. This study analysed changes in global radiation in Hai River basin, China during 1960 to 2012. Global radiation decreased significantly from 1960 to 1989 and increased from 1990 to 2012, which has been described as "from dimming to brightening". Sunshine duration was used as a proxy index where radiation records were unavailable. Results showed that sunshine duration (for 45 stations) show a significant decreasing trend from 1960 to 2012, which was a little different to global radiation (for 6 stations) during the brightening phase. Penman-Monteith model was used for estimating trends of reference evapotranspiration. The consistency of temporal and spatial variations in sunshine duration and reference evapotranspiration was examined during the periods 1960-1989 and 1990-2012. The results showed that the annual reference evapotranspiration trend was consistent with the sunshine duration trend (both were decreasing for 37 of the 45 stations) during 1960 to 1989 , followed by an upward trend (for 26 of the 45 stations) from 1990, while the annual sunshine duration indicated a downward trend (for all 45 stations) during the whole period 1960-2012. Overall, global dimming could be the dominant factor for the decreased reference evapotranspiration from 1960 to 1989, while the increased reference evapotranspiration from 1990 to 2012 could be driven by other meteorological variables, especially global warming.
\end{abstract}

Key words global dimming; sunshine duration; reference evapotranspiration; China

\section{INTRODUCTION}

Global radiation, the sum of direct radiation and diffuse radiation, is the fundamental energy source for life and the main driving factor of land surface processes, such as evaporation, plant photosynthesis and snow melt. Much literature has confirmed declines of global radiation, which is named as "global dimming", between the 1950s and the 1980s in many places around the globe (Stanhill and Cohen, 2001). However, many recent studies using solar radiation records updated to the year 2000 have found a reverse trend named "brightening" since the 1980s (Wild et al., 2005). The latest updates on developments beyond the year 2000 showed mixed tendencies, and there is some indication of a renewed dimming in China (Wild, 2012).

The surface radiation balance is the principal driver of the global hydrological cycle (Wild and Liepert, 2010), and the connecting term between the water and energy balance is evapotranspiration. The hydrological cycle has intensified in many parts of the world during the 20th century (Huntington, 2006), along with the increasing global temperature. However, contrary to the expectation that a warmer climate will increase evaporation, many studies have reported decreasing pan evaporation or reference evapotranspiration over the past 50 years (Roderick and Farquhar, 2002; Liu et al., 2004), a situation termed the "evaporation paradox". There is not yet a definite conclusion about the mechanism of the evaporation paradox (Cong et al., 2008). Previous studies based on qualitative analysis found that the decrease of global radiation may be the best explanation of the evaporation paradox (Teuling et al., 2009; Papaioannou et al., 2011; Matsoukas et al., 2011; Zhang et al., 2012), but further quantitative proof is needed.

The Hai River basin is one of the most important crop planting areas in China. Changes in global radiation could impact agricultural water consumption in this basin. However, the quantitative impact of global dimming and brightening on reference evapotranspiration is seldom studied in the literature. The objectives of this study are: (1) to characterize the temporal and spatial changes in global radiation and sunshine duration in Hai River basin from 1960 to 2012; and (2) to analyse the impact of changing sunshine duration on reference evapotranspiration. 


\section{MATERIALS AND METHODS}

\subsection{Study area}

Hai River basin is located in North China. The catchment covers an area of $318000 \mathrm{~km}^{2}$ and lies at an elevations of -64 to $3059 \mathrm{~m}$ (Fig. 1). The predominant climate is the Asian Monsoon climate with cold and dry winters, and hot and rainy summers. Annual precipitation is $380-800 \mathrm{~mm}$, about $75 \%$ of which falls in the rainy months June to September. Annual average temperature is $9.5-12.5^{\circ} \mathrm{C}$. The annual global radiation is about $4500-6000 \mathrm{MJ} / \mathrm{m}^{2}$ per year.

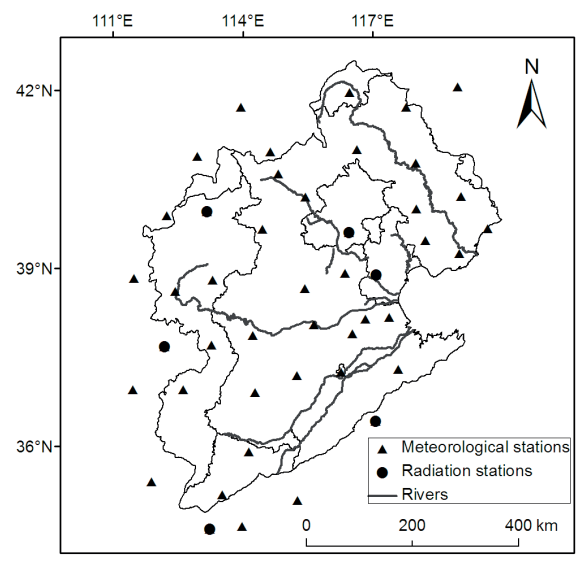

Fig. 1 Location of the 45 meteorological stations (six with radiation records) in Hai River basin.

\subsection{Data}

This study used the monthly radiation records of six meteorological stations in the Hai River basin (Fig. 1) from 1960 to 2012. Monthly measurements of sunshine duration, maximum air temperature, minimum air temperature, wind velocity and relative humidity for 45 stations in and around Hai River basin, from the National Meteorological Information Centre of China, were used for estimating reference evapotranspiration by the Penman-Monteith equation (Allen, 1998):

$$
E T_{0}=\frac{0.408 \Delta\left(R_{n}-G\right)+\gamma \frac{900}{T+273} \mu_{2}\left(e_{s}-e_{a}\right)}{\Delta+\gamma\left(1+0.34 u_{2}\right)}
$$

where $E T_{0}$ is reference evapotranspiration $\left(\mathrm{mm} \mathrm{day}^{-1}\right), R_{n}$ is net radiation at the crop surface (MJ $\mathrm{m}^{-2}$ day $\left.^{-1}\right), G$ is soil heat flux density $\left(\mathrm{MJ} \mathrm{m}^{-2}\right.$ day $\left.^{-1}\right), T$ is air temperature at $2 \mathrm{~m}$ height $\left({ }^{\circ} \mathrm{C}\right), u_{2}$ is wind speed at $2 \mathrm{~m}$ height $\left(\mathrm{m} \mathrm{s}^{-1}\right), e_{s}$ and $e_{a}$ are saturation and actual vapor pressure $(\mathrm{kPa}), \Delta$ is slope vapour pressure curve $\left(\mathrm{kPa}{ }^{\circ} \mathrm{C}^{-1}\right)$, and $\gamma$ is psychrometric constant $\left(\mathrm{kPa}^{\circ} \mathrm{C}^{-1}\right)$. More details about the parameters and calculation procedure are presented in Allen (1998).

\subsection{Method}

The significance of trends of solar radiation, sunshine duration and reference evapotranspiration in historical time series was analysed by the non-parametric Mann Kendall test (Mann 1945, Kendall 1975), which is frequently used with climatic time series (Papaioannou et al., 2011; Zhang et al., 2012). It is described in Yang et al. (2009). Pearson correlation analysis was used to detect the relationship between sunshine duration and reference evapotranspiration.

\section{RESULTS}

\subsection{Changes in global radiation and sunshine duration}

The regional variation of annual global radiation averaged from the six stations is shown in Fig. 2. The trend of global radiation change is tested by the Mann Kendall method. Results show that 
solar radiation decreased significantly $(Z=-4.85, P<0.001)$ from 1960 to 1989 at a rate of 27.97 $\mathrm{MJ} \mathrm{m}^{-2}$ per year, and slightly increased $(\mathrm{Z}=0.32, \mathrm{P}>0.1)$ at a rate of $2.27 \mathrm{MJ} \mathrm{m}^{-2}$ per year from 1990 to 2012. Therefore, global radiation change in the Hai River basin fits the pattern of "from dimming to brightening" (Wild et al., 2005).

Solar radiation data are not readily available in many places due to the cost, maintenance and calibration requirements of the measuring equipment. To estimate temporal and spatial variations over the whole region, sunshine duration is used as the proxy for solar radiation. Figure 3 shows the regional variation of annual sunshine duration averaged from the 45 stations in and around Hai River basin from 1960 to 2012. During the period 1960 to 1989, sunshine duration decreased significantly $(Z=-2.57, P<0.05)$ at a rate of 6.23 hours per year, which was consistent with the variation of solar radiation in the same period. However, from 1990 to 2012, sunshine duration also decreased significantly $(\mathrm{Z}=-2.54, \mathrm{P}<0.05)$ at a rate of 7.13 hours per year, which was opposite to trend of solar radiation. In fact, the results showed that sunshine duration (for 45 stations) showed a significant decreasing trend from 1960 to 2012, which was a little different to the global radiation (for 6 stations). This indicates that data at more stations are necessary to estimate more exactly the variation trend of solar radiation for the whole region.

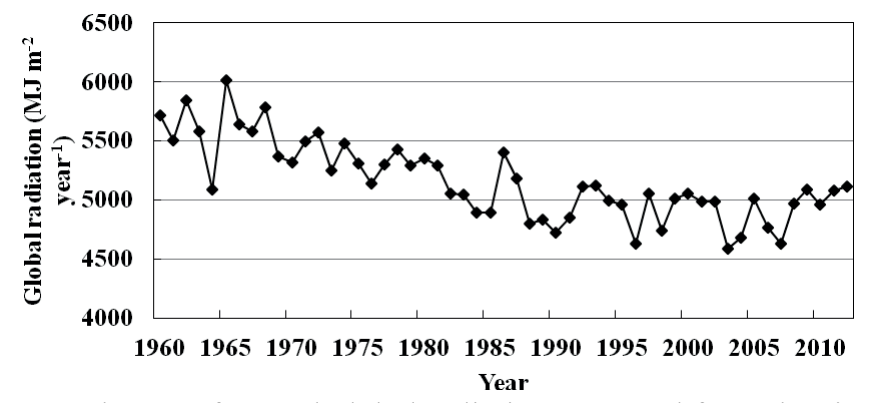

Fig. 2 Change of annual global radiation averaged from the six stations in Hai River basin 1960-2012.

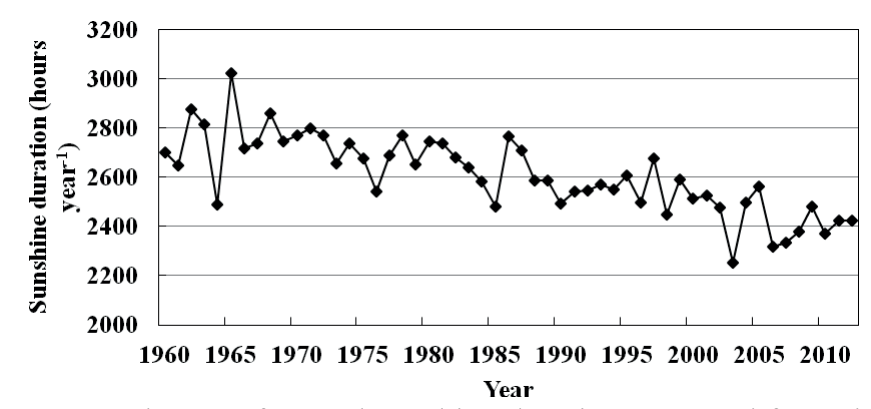

Fig. 3 Change of annual sunshine duration averaged from the 45 stations in and around Hai River basin from 1960 to 2012 .

To compare the different variations of sunshine duration between the two periods for each station, trends in annual sunshine duration for the 45 stations in and around Hai River basin during the two periods are shown in Fig. 4 (S indicates significantly and NS indicates non-significantly). During the period 1960 to 1989 , sunshine duration decreased at 38 stations (significantly at 19 stations located in the south and non-significantly in 19 stations of the central region), but increased at 7 stations (significantly at 3 stations and non-significantly at 4 stations) which are mainly located in the northwest of the Hai River basin (Fig. 4(a)). Moreover, from 1990 to 2012, sunshine duration also decreased at 38 stations (significantly at 22 stations and non-significantly at 16 stations) but increased at 7 stations (significantly at 1 station and non-significantly at 6 stations) (Fig. 4(b)). It is worth noting that stations with increasing trend in the former period were not consistent with that in the later period, except for Duolun station. There were 32 stations always dimming, 6 stations changed from dimming to brightening, 6 stations from brightening to dimming, and 1 station always brightening during the two periods. Thus, most stations, which should represent the regional condition, showed a decreasing trend for the whole period of 1960 to 2012. 


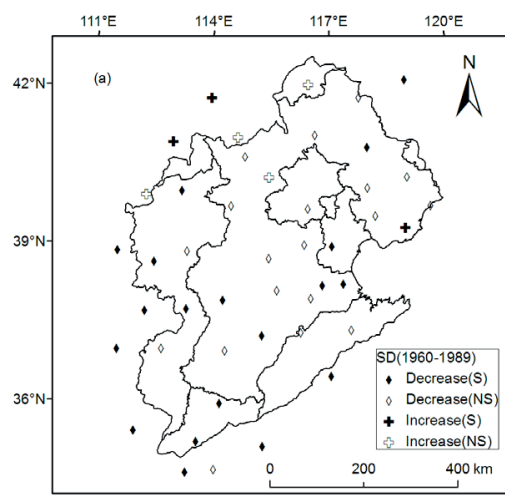

(a)

Fig. 4 Trends in annual sunshine duration for the 45 stations in and around Hai River basin during (a) 1960 to 1989 , and (b) 1990 to 2012 .

\subsection{Impact of sunshine duration on reference evapotranspiration}

Evapotranspiration, which is an important process in the surface water cycle, could be affected by solar radiation and sunshine duration. In this study, the consistency of temporal and spatial variations in sunshine duration and reference evapotranspiration was examined during the periods 1960-1989 and 1990-2012.

Figure 5 shows the regional variation of annual reference evapotranspiration averaged from the 45 stations in and around Hai River basin from 1960 to 2012. During the period 1960 to 1989 , reference evapotranspiration decreased significantly $(\mathrm{Z}=-2.68, \mathrm{P}<0.01)$ at a rate of $1.90 \mathrm{~mm}$ per year, which was consistent with the variation of solar radiation and sunshine duration in the same period. However, from 1990 to 2012, reference evapotranspiration increased $(Z=1.16, P>0.1)$ at a rate of $0.95 \mathrm{~mm}$ per year, which was consistent with the variation of solar radiation but opposite to the trend of sunshine duration. The result indicates that the evaporation paradox existed during the period 1960 to 1989, but has disappeared since 1990. This also implies that there were some other climate factors driving the variation of evapotranspiration during 1990 to 2012.

To compare spatial variations in sunshine duration and reference evapotranspiration, trends in annual reference evapotranspiration for the 45 stations in and around Hai River basin during the periods 1960-1989 and 1990-2012 are shown in Fig. 6. During the period 1960 to 1989, reference evapotranspiration decreased in 40 stations (significantly in 18 stations located in the south and non-significantly in 22 stations located in the north region) but increased in 5 stations (nonsignificantly in all stations) which mainly located in the northwest of Hai River basin (Fig. 6a). However, from 1990 to 2012, reference evapotranspiration increased in 26 stations (significantly in 10 stations and non-significantly in 16 stations) but decreased in 19 stations (significantly in 3 station and non-significantly in 16 stations) (Fig. 6(b)). In other words, most stations show increasing or non-significantly decreasing trend since 1990, which could correspond to global warming and hydrological intensification.

Comparing variation trends of sunshine duration and evapotranspiration at individual stations, the annual reference evapotranspiration trends were consistent with the sunshine duration trend at 40 stations (both were decreasing for 37 and increasing for 3 stations) during 1960 to 1989, while they were consistent for just 21 stations (both were decreasing for 16 and increasing for 5 stations) from 1990. However, from the results of the Pearson correlation analysis, sunshine duration was correlated significantly with reference evapotranspiration during 1960 to 2012 at all the stations, except Wutaishan. This indicates that the changes in sunshine duration may be the primary factor influencing reference evapotranspiration in the period 1960 to 1989, but it could not interpreted as changing reference evapotranspiration for the period of 1990 to 2012. There are many other climatic factors, such as temperature, relative humidity and wind speed, which may be the most sensitive parameters to reference evapotranspiration. Thus, more quantitative analysis on the relationship between evapotranspiration and its impact factors, including solar radiation, is needed. 


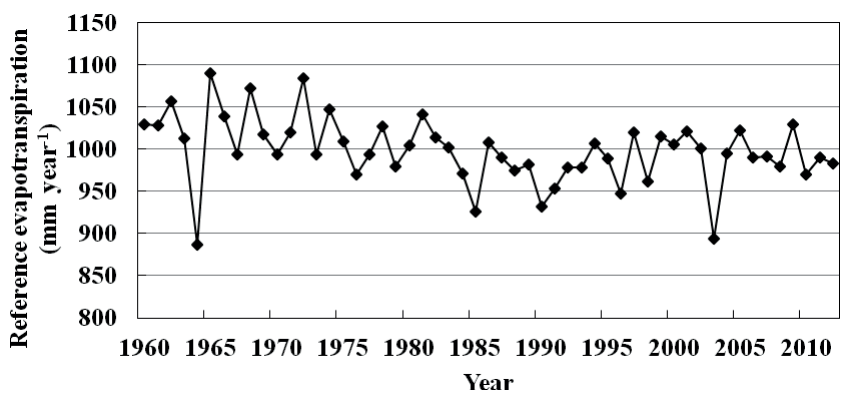

Fig. 5 Change of annual reference evapotranspiration averaged from the 45 stations in Hai River basin from 1960 to 2012 .

(a)

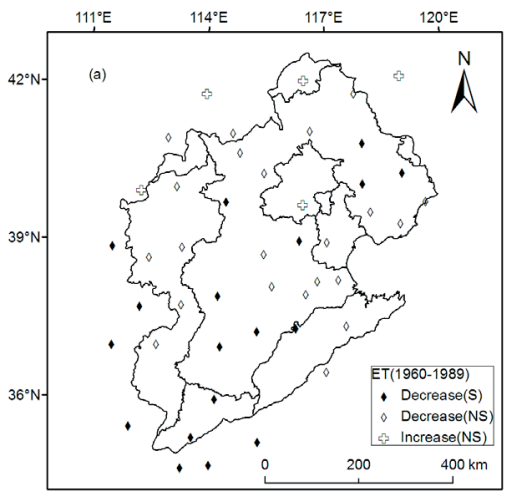

(b)

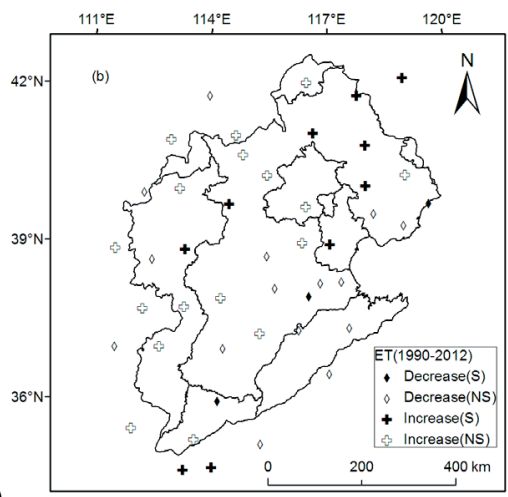

Fig. 6 Trends in annual reference evapotranspiration for the 45 stations in and around Hai River basin during (a) 1960 to 1989, and (b) 1990 to 2012.

\section{DISCUSSION}

Global dimming and brightening is one of the most important issues in the field of climate change (Alpert et al., 2005; Streets et al., 2006; Wild, 2009). In this study, variations of solar radiation in Hai River basin fit the pattern of global dimming and brightening. However, the change in sunshine duration, which shows always dimming from 1960 to 2012, does not corresponding with the change in solar radiation. There are so few stations with solar radiation records that their average variation could not be used represent conditions of the whole region. Another possible reason is that change of sunshine duration is not in thorough agreement with that of solar radiation at each station, especially during the period 1990 to 2012. Moreover, variation of sunshine duration in this study is not consistent with that in the Yangtze River basin of China (Zhang et al., 2012). It is suggested that further investigation be conducted on the complex feedback mechanisms between solar radiation and sunshine duration.

Evapotranspiration is a key link between the water cycle and energy cycle. It is apparent from previous studies that the changing solar radiation could impact the water cycle via evapotranspiration change (Wild, 2012). Researchers found that the amplitude of decrease in solar radiation played the most important role in the decrease in evapotranspiration in the southern part of China before the early 1990s, while solar radiation was less important than temperature and water vapour after the early 1990s (Xu et al., 2006; Liu et al., 2011). This is consistent with results in this study. The number mismatches of stations between reference evapotranspiration and sunshine duration indicate that the separate changes in sunshine duration or solar radiation could not interpret the change in reference evapotranspiration exactly. Therefore, global dimming could be the dominating factor for the decreased reference evapotranspiration from 1960 to 1989, while the increased reference evapotranspiration from 1990 to 2012 could be driven by other meteorological variables, especially global warming. 


\section{CONCLUSIONS}

Changes in global radiation could impact the energy - water balance, hydrological cycle and agricultural water consumption in Hai River basin, China. This study analysed changes in global radiation, sunshine duration and reference evapotranspiration during 1960 to 2012. Global radiation decreased significantly from 1960 to 1989 and increased from 1990 to 2012, which has been described as "from dimming to brightening". Sunshine duration (for 45 stations) show a significant decreasing trend from 1960 to 2012, which was rather different to global radiation (for 6 stations) during the brightening phase. The consistency of temporal and spatial variations in sunshine duration and reference evapotranspiration was examined during the periods 1960-1989 and 1990-2012. The results show that the annual reference evapotranspiration trend was consistent with the sunshine duration trend during 1960 to 1989 , followed by an upward trend from 1990, while the annual sunshine duration indicated a downward trend during the whole period, 1960-2012. Thus, global dimming could be the dominating factor for the decreased reference evapotranspiration in the former period, while the increased reference evapotranspiration since 1990 could be driven by other meteorological variables, especially global warming.

Acknowledgements This research was supported by the National Natural Science Foundation of China (No. 51409109), the Fundamental Research Funds for the Central Universities, HUST: 2014QN234, open foundation of Key Laboratory of Agricultural Water Resources and Hebei Key Laboratory of Agricultural Water-Saving, Center for Agricultural Resources Research, Institute of Genetics and Developmental Biology, Chinese Academy of Sciences (KF311201303082), and the Open Research Fund of State Key Laboratory of Simulation and Regulation of Water Cycle in River Basin (China Institute of Water Resources and Hydropower Research) (No. IWHR-SKL-201308).

\section{REFERENCES}

Allen, R.G. et al. (1998) Crop evapotranspiration - Guidelines for computing crop water requirements. FAO Irrigation and Drainage Paper 56 Rome, Italy.

Alpert, P. et al. (2005) Global dimming or local dimming? Effect of urbanization on sunlight availability. Geophysical Research Letters 32, L17802.

Cong, Z., et al. (2008) Evaporation paradox in China. Advances in Water Science 19(2), 147-153 (in Chinese with English abstract)

Huntington, T.G. (2006) Evidence for intensification of the global water cycle: Review and synthesis. Journal of Hydrology 319, 83-95.

Kendall, M.G. (1975) Rank Correlation Methods. Griffin, London.

Liu B., et al. (2004) A spatial analysis of pan evaporation trends in China, 1955-2000. Journal of Geophysical Research 109, D15102.

Liu X., et al. (2011) Recent changes in pan-evaporation dynamics in China. Geophysical Research Letters 38(13), L13404.

Mann, H.B. (1945) Nonparametric tests against trend. Econometrica: Journal of the Econometric Society 13, $245-259$.

Matsoukas, C., et al. (2011) Potential evaporation trends over land between 1983-2008: driven by radiative fluxes or vapourpressure deficit? Atmos. Chem. Phys. 11, 7601-7616

Papaioannou, G., Kitsara, G. and Athanasatos, S. (2011) Impact of global dimming and brightening on reference evapotranspiration in Greece. Journal of Geophysical Research 116, D09107.

Roderick, M. L. and Farquhar, G. D. (2002) The cause of decreased pan evaporation over the past 50 years. Science 298, 1410-1411.

Stanhill, G. and Cohen, S. (2001) Global dimming: a review of the evidence for a widespread and significant reduction in global radiation with discussion of its probable causes and possible agricultural consequences. Agricultural and Forest Meteorology 107, 255-278.

Streets, D.G., Wu, Y. and Chin, M. (2006) Two-decadal aerosol trends as a likely explanation of the global dimming/brightening transition. Geophysical Research Letters 33, L15806.

Teuling, A. J., Hirschi, M. and Ohmura, A. (2009) A regional perspective on trends in continental evaporation. Geophysical Research Letters 36: L02404, doi:10.1029/2008GL036584

Wild, M. (2009) Global dimming and brightening: a review. Journal of Geophysical Research 114, D00D16.

Wild, M. (2012) Enlightening global dimming and brightening. Bulletin of the American Meteorological Society 93, $27-37$.

Wild, M., et al. (2005) From dimming to brightening: decadal changes in solar radiation at Earth's surface. Science 308, 847-850.

Wild, M. and Liepert B. (2010) The earth radiation balance as the driver of the global hydrological cycle. Environmental Research Letters 5, 1-8.

$\mathrm{Xu}, \mathrm{C}$., et al. (2006) Analysis of spatial distribution and temporal trend of reference evapotranspiration and pan evaporation in Changjiang (Yangtze River) catchment. Journal of Hydrology 327(1-2), 81-93.

Yang, Y., et al. (2009) Effect of wind speed on sunshine hours in three cities in northern China. Climate Research 39, $149-157$.

Zhang, D., Liu C. and Liu X. (2012) Change in global radiation and its impacts on the water cycle in the Yangtze River basin from 1961 to 2010. Water International 37(5), 598-610. 